\title{
JESUS AS BRUGBOUER: JESUS EN DIE BUITESTANDERS IN JOHANNES 4:1-42
}

\author{
Bennie Marais, Universiteit van Pretoria \\ Ernest van Eck, Universiteit van Pretoria \\ Jacobus Kok, ETF Leuven, België en Universiteit van Pretoria
}

\begin{abstract}
This article deals with Jesus and the outsiders in John 4, with particular focus on John 4:1-42. Methodologically, the study focuses on social identity theory, and asks the question of how Jesus gets the Samaritan woman, who is a member of the outside group, into the insider group. The focus of the study is thus what the behaviour and attitude of the historical and nonconventional Jesus was toward outsiders in the strongly hierarchical social structure of his day.
\end{abstract}

\section{Inleiding}

Hierdie artikel het as fokus die verhouding tussen Jesus en die buitestanders (die Samaritaanse vrou) in Johannes 4:1-42. Die betrokke vertelling word gelees deur die heuristiese bril van sosiale-identiteitsteorie, en daar word aangetoon dat die lens van hierdie teorie 'n nuwe of minstens meer genuanseerde verstaan van die vertelling na vore bring. Die vraag wat die artikel poog om te beantwoord, is die volgende: Hoe het Jesus die Samaritaanse vrou, wat deel van die buitegroep was, in die binnegroep gekry? In wese fokus die artikel dus eintlik op die historiese- en nie-konvensionele Jesus se houding en optrede teenoor buitestanders binne die streng hiërargiese sosiale- en reinheidstruktuur van sy dag.

\section{Sosiale-identiteitsteorie in Nuwe Testamentiese studies}

Sosiale-identiteitsteorie is ontwikkel deur Tajfel (1978; 1981; 1982), Tajfel en Turner (1986) en Turner (1987; 1996). ${ }^{1}$ In die Nuwe Testamentiese Wetenskap is dit deur Philip Esler vir die eerste keer rondom 1996 met veel vrug gebruik (kyk Esler 2003). Onlangs (2014) het die T\&T Clark Handbook to Social Identity in the New Testament verskyn onder die redakteurskap van Brian Tucker en Coleman Baker. Hierdie teoretiese benadering tot die tekste het ten doel om eksplisiet te maak wat alreeds op sosiaal-dinamiese vlak implisiet in die teks lê. Die teorie funksioneer as heuristiese lens en word abduktief aangewend (Joubert \& Van Aarde 2009:419-455).

Sosiale-identiteitsteorie definieer sosiale identiteit as 'the aspects of an individual's selfimage that derive from the social categories to which he perceives himself as belonging' (Turner 1996:16), en bestudeer die verhouding tussen 'n individu se selfverstaan en die-

Tajfel baseer sy teorie oor identiteit op sy sogenaamde 'minimale groepseksperiment'. In 'n situasie waarin deelnemers georganiseer is in groepe wat anoniem en na willekeur saamgestel is sonder enige voorafkontak, het dit geblyk dat groepsbelange swaarder weeg as persoonlike selfbelange (Tajfel 1978:149-178). Tajfel het verder deur hierdie eksperiment aangetoon hoe die prosesse van groepkategorisering verloop, en hoe hierdie prosesse intergroep-gedrag beïnvloed. Groepvorming, aldus Tajfel, is dus in wese sosiale kategorisering (Billing \& Tajfel 1973:27-52). 
selfde individu se deel-wees van 'n groep. Sosiale-identiteitsteorie gaan van die oortuiging uit dat die meeste persone (veral persone wat deel is van 'n kollektiewe kultuur soos die eerste-eeuse Mediterreense wêreld), se selfverstaan grootliks gevorm word deur die feit dat hulle aan 'n bepaalde groep behoort. So verstaan, bestaan sosiale identiteit uit 'n kognitiewe, emosionele en evaluerende komponent. ${ }^{2}$ Sosiale-identiteitsteorie is verder van oordeel dat lidmaatskap tot 'n bepaalde groep nie staties is nie. Die deel-wees van 'n bepaalde groep kan iemand tot ander insigte bring oor bepaalde groepe, en sterk leierskap kan persone bring om aan meer as een groep te behoort (Esler 2003). Deur die herdefiniëring van groepsgrense, byvoorbeeld as gevolg van leierskap, kan persone wat aanvanklik beskou was as deel van 'n buitegroep opgeneem word in die binnegroep (Capozza \& Brown 2000:xiv).

Tajfel (1981:1) het verder aangetoon dat verskillende groepe (bv. nasionale, etniese en taalgroepe) se fokus die behoud van 'n 'eiesoortigheid' is, ten spyte van toenemende vlakke van kommunikasie en interafhanklikheid met ander groepe (Tajfel 1978:2). Saam met Turner het Tajfel ook spesifiek aandag gegee aan intergroep-konflik (Tajfel \& Turner 2001:33-47). Wat hier van belang is, is dat daar dikwels 'n verskil is tussen die wyse waarop individue teenoor mekaar optree as individue, en hoe dieselfde persone teenoor mekaar optree as lede van dieselfde groep (Tajfel 1978:7). Tajfel (1978:43) het verder ook aangetoon dat lede van dieselfde groep se houding teenoor lede van 'n buitegroep meer eenvormigheid vertoon, en dat lede van 'n binnegroep geneig is om individuele verskille met buitegroeplede te ignoreer en ongedifferensieerd te beskou as deel van 'n homogene sosiale kategorie (Tajfel 1978:44-45). Kortom kom sosiale-identiteitsteorie dus daarop neer dat wanneer sosiale kategorisering met sosiale identiteit gekoppel word, die gevolg 'sosiale vergelyking' is. Die individu se begrip van wie hy of sy is, word bepaal deur die groep waaraan so 'n persoon behoort, en hoe hierdie groep verskil van ander groepe in terme van aspekte soos status, rykdom, armoede of etniese identiteit.

\section{Buitestanders, Jesus en die status quo}

In die kontekstuele en referensiële buite-tekstuele wêrelde (die wêreld[e] agter die teks) word Samaritane meestal vanuit die perspektief van behoudende strominge binne die vroeë Judaïsme as buitestanders getipeer (kyk bv. Joh. 4; 8:1-11, 48; vgl. Snodgrass ${ }^{3}$ 2018: ad

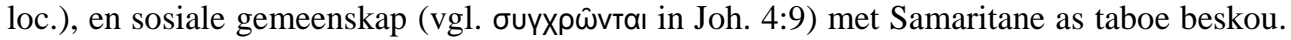
Dit word die duidelikste gesien in primêre antieke tekste soos in die Babiloniese Talmoed en spesifiek in Nidah $4: 1 ; 31$ b en 56b waarvolgens die dogters van die Samaritane beskou word as onrein van hulle geboorte af, en dit waaraan hulle raak of waarop hulle skadu val ipso facto onrein is. Snodgrass (2018) toon verskeie primêre antieke bronne, ook nader aan die tyd van Johannes aan, wat hierdie spanning tussen Jode en Samaritane illustreer (bv. Sirach 50:25-26; Josephus, Ant 12:10; 13:275-281; 18:29-30; 20:118-136; m. Šeqalim 1:5; m. Šebi it 8:10). ${ }^{4}$

\footnotetext{
2 Die kognitiewe komponent bestaan uit die wete dat ek tot 'n bepaalde groep behoort, die emosionele komponent is die emosionele binding aan die waardes van die groep, en die evaluerende komponent is die houding van hulle wat aan die binnegroep behoort teenoor hulle wat aan buitegroepe behoort (Tajfel 1978:28-29).

3 Snodgrass (2018:347) verwys in sy boek Stories with intent: A comprehensive guide to the parables of Jesus, na Josephus en die negatiewe gevoelens tussen Jode en Samaritane gedurende die middel van die eerste eeu (circa 50 n.C.).

4 Daar was natuurlik ook uitsonderings op die reël en sommige rabbi's (soos Akiba) het verskil van ander rabbi's. Akiba, byvoorbeeld, verwerp die radikale uitspraak van Rabbi Eliezer in m. Šebi'it 8:10 (vgl. Snodgrass 2018:347).
} 
Johannes self bied in sy narratief (die wêreld ín die teks) eksplisiet hierdie spanning aan as synde 'n realiteit, en lig die implisiete leser wat dalk nie van hierdie spanning bewus is nie, daarvan in. Hy doen dit deur die woorde wat in die mond van die Samaritaanse vrou by die put gelê word. Die vrou self vra aan Jesus: Hoe is dit dat u, 'n Jood, vir my, 'n Samaritaanse vrou iets vra om te drink ... want (let wel, die negatiewe redegewende voegwoord/partikel in die konstruksie oủ yà $\rho)$ Jode gaan immers nie met Samaritane om nie

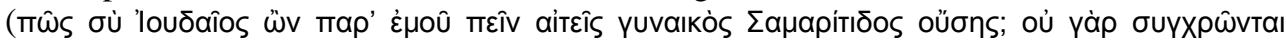

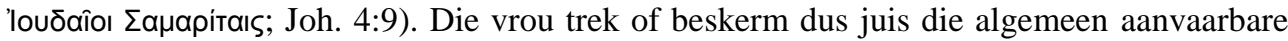
sosiale grense, in ' $\mathrm{n}$ konteks waar Jesus die grense transendeer en Jesus nie die status quo handhaaf nie, en toenemende sosiale interaksie inisieer.

Die spanning tussen die Jode en die Samaritane strek sover terug as $722 \mathrm{vC}$, toe die Assiriërs die Noordelike koninkryk van Israel ingeval het. Van die Jode wat nie in ballingskap weggevoer is nie, het ondertrou met van die Assiriërs, en so het die Samaritane ontstaan (Barclay 2000:149). Die verbastering was vir die Israeliete van die Suidelike Ryk 'n skande - die verlies van hulle eksklusief-Israelities etniese suiwerheid. Die Jode het die Samaritane as vreemdelinge beskou ('n volk met gemengde bloed van Jood en Assiriër), ongelowiges en afgodedienaars (kyk 2 Kon. 17:6-41). Die Samaritane het egter nog steeds die Tora aanvaar, en die plek van aanbidding as Geresim (digby die moderne Nablus) gesien. Die tempel by Geresim is gebou terwyl daar nie 'n tempel in Jerusalem was nie. Johannes Hyrcanus (die Makkabese leier vanaf 134-104 vC) het hierdie tempel verwoes (128 vC), wat natuurlik die vyandigheid tussen die Jode en Samaritane verder verhoog het. As teenreaksie op die verwoesting van hulle tempel, het sommige Samaritane die tempelplein in Jerusalem met beendere van dooie mense en diere bestrooi - beendere wat as onrein beskou is omdat dit vanaf dooie wesens kom. Vir die Jode was die tempelplein dus met die 'dood' besaai, en ontheilig deur die Samaritane. As reaksie hierop is alle Samaritane die toegang tot alle sinagoges verbied, en tydens die gebede in die sinagoges is gevra dat hulle ook van die ewige lewe uitgesluit sal word. Die Johannesevangelie weerspieël iets van hierdie spanning tussen Jood en Samaritaan. In Johannes 8:48, byvoorbeeld, sien ons dat die Jode die Samaritane beskou het as synde binne die kategorie van die kinders van die Satan, en in hulle gesprek met Jesus, omdat hulle van Hom verskil oor sy identiteit, hom tipeer as 'n Samaritaan wat van die duiwel besete is.

Johannes 4:1-42 kan beskou word as een van die mees treffende voorbeelde van die positiewe uitbeelding van 'n getransformeerde 'buitestander' of 'die ander' in die Evangelie. Nie alleen was sy iemand met 'n twyfelagtige huwelikstatus nie, maar boonop 'n onrein Samaritaan en dus iemand wat as gemarginaliseerde vanuit 'n behoudende vroegJoodse perspektief gekets word. ${ }^{5}$ Die vrou in Johannes 4 is daarom miskien een van die beste voorbeelde in die Evangelie om Jesus se houding teenoor die buitestanders (en Johannes se algemene positiewe aanbieding van vroue) te ondersoek - iemand met verkeerde geslag, van verkeerde etnisiteit wat op die verkeerde plek of ruimte Jesus ontmoet.

Anibati-Abia (2013:3-6) gee 'n goeie oorsig oor die geskiedenis van navorsing en die verskillende perspektiewe op die Samaritaanse vrou as synde 'n owerspelige vrou of nie. Daar is verskeie argumente in die kerkgeskiedenis en historiese kerklike kommentare en ook deur moderne navorsers. Sommige geleerdes beskou haar as 'n oneervolle vrou en andere as 'n produk van 'n patriargale sisteem, dus dat haar posisie nie die gevolg was van immorele gedrag nie. Die meeste geleerdes is dit egter eens dat Johannes hier, soos elders

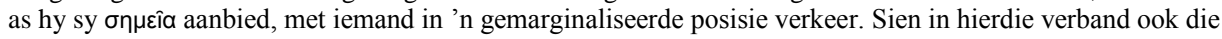
soortgelyke gevolgtrekking waartoe Kok (2016) kom. 


\section{Johannes 4:1-42 deur die lens van sosiale-identiteitsteorie}

Vanuit die perspektief van sosiale-identiteitsteorie identifiseer Johannes 4:1 die leiersrol van Jesus; Hy doop meer mense en maak meer dissipels as Johannes. Die feit dat die Fariseërs hierdie berig hoor, dui verder onmiddellik op groepvorming. In die binnegroep gaan dit goed, maar nie in die buitegroep nie (Malina \& Rohrbaugh 1998:98). Duidelik is Johannes 4:1 ondubbelsinnig ten gunste van die lede van die eie groep teenoor lede van die buitegroep. Jesus is die leier, en sy groep is beter daaraan toe as die buitegroep.

Wanneer die leier van die binnegroep in Sigar ${ }^{6}$ aankom, verskyn die tweede buitegroep in die vertelling op die toneel. Jesus, 'n Jood, ontmoet 'n Samaritaanse vrou. Belangrik is waar Jesus haar ontmoet, te wete by die fontein of put van Jakob. Vir die Samaritane was hierdie put belangrik, aangesien dit hulle oorsprong aan die begin van die koninkryk van Israel koppel: hulle voorvader is Jakob (Joh. 4:12). In die vrou se eerste opmerking is die konflik tussen die twee groepe (Jode en Samaritane) duidelik: Jode en Samaritane gaan nie met mekaar om nie. Immers, die Samaritane aanbid by Geresim, en die Jode in Jerusalem (Joh. 4:20). Duidelik is hier dus twee buitegroepe ter sprake, met veral die een buitegroep (die Samaritane) wat die klem op hulle eiesoortigheid laat val.

Wat meer is, is dat hierdie buitegroep heel waarskynlik deur 'n 'laerklas' vrou verteenwoordig word. 'n Put was 'n plek waar veral laerklas vroue gereeld bymekaargekom het. Dit was hulle daaglikse taak om hier vars water vir die huishouding te gaan haal. Normaalweg het die vroue vroeg in die oggend of in die aand - wanneer dit koel was - gaan water skep (kyk bv. Gen. 24:11). Die vroue het gewoonlik nie op hulle eie nie, maar saam met ander vroue gaan water skep (1 Sam. 9:11), en terwyl hulle daar was, was die put effektief die vroue se 'private' ruimte (Malina \& Rohrbaugh 1998:98). Die feit dat die vrou alleen by die put was, en dat van die dorp se ander vroue nie daar was nie, laat die suggestie dat die ander vroue haar vermy het. Sy is heel waarskynlik gesien as sosiaal afwykend (Joh. 4:16$18)$.

Dat Jesus alleen met ' $n$ vrou praat, is in wese verrassend. Daar is van mans verwag om nie met vreemde vroue te praat in die publiek nie. Die verteller beklemtoon dat hulle alleen was (Joh. 4:8), en dat die vrou verbaas was dat Jesus met haar praat. Haar antwoord aan Jesus beklemtoon dat sy vroulik en 'n Samaritaan is, terwyl Jesus manlik en 'n buitestander (Jood) is. Hierdie soort bewustheid van geslag en herkoms was tipies van sosiale interaksie in die antieke tyd (Malina \& Rohrbaugh 1998:98). Sosiale-identiteitsteorie help ons om hierdie interaksie beter te verstaan, veral dat daar in die gesprek 'n verwisseling tussen private en openbare ruimte plaasvind.

Die verteller se woordkeuse in Johannes 4:9 beklemtoon die kontras tussen die twee groepe wat hier deur Jesus en die Samaritaanse vrou verteenwoordig word. Die Griekse

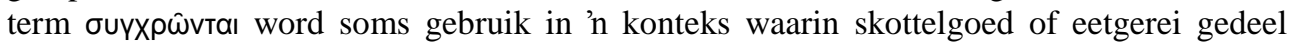
word. Dit gaan dus hier oor 'n bekommernis oor rituele reinheid, aangesien die Jode van oordeel was dat Samaritaanse vroue permanent onrein was: "die susters van die Samaritane menstrueer vanaf die wieg" (kyk m. Nid. 4.1). Volgens Levitikus 15:19-27 was nie net 'n vrou wat menstrueer onrein nie, maar ook enigeen wat bloot aan items wat sy hanteer het, sou raak. Verder, as 'n vrou gebly het by 'n man wat nie haar man was nie, is sy ook as

Die klein dorpie Sigar (die moderne Askar) is ongeveer twee myl oos van Nablus geleë, net oos van die berg Geresim en die berg Ebal (Kippenberg 1971:94). Die identifisering van Sigar as die Bybelse Sigem (ongeveer 'n myl van Askar) is onwaarskynlik, omdat Sigem waarskynlik in 128 vC (of ten minste voor 107 vC) deur die Hasmoniese hoëpriester John Hyrcanus I vernietig is. Na die verowering van Jerusalem deur die Romeinse generaal Pompeii (63 vC), is Sigar vervang deur Sigem as die belangrikste Samaritaanse stad (Albright 1956:160). 
oneervol en onrein beskou. Uit 'n Judeër se waardes is hierdie hele toneel as sosiaal afwykend beskou, en dit beklemtoon die stereotipering van die binnegroep teenoor die buitegroep (Malina \& Rohrbaugh 1998:98).

Dit is verder interessant dat die vrou, 'n Samaritaan, Jesus 'n Judeër ( $\sigma$ ù 'louס̃ẫo in Joh. 4:9) noem. In Johannes 8:48 noem die Judeërs Jesus 'n Samaritaan. Om iemand op 'n afwysende en vilifiserende wyse name te noem was 'n manier om iemand uit te wys as 'n buitestander. Jesus - 'n Galileër - is letterlik vir beide groepe 'n buitestander. Vir enige groep sou dit doodnormaal wees om die etikette te gebruik om mekaar voor te stel en die sosiale afstand tussen hulself en Jesus uit te druk (Malina \& Rohrbaugh 1998:99).

Jesus transendeer egter al hierdie aspekte van taboe en afwysing wanneer hy met die (onrein) Samaritaanse vrou praat en bereid is om saam met haar uit dieselfde beker te drink. Wanneer hy dit doen, behandel hy die vrou as 'n gelyke en dus in wese as 'n familielid of binnestaander (Neyrey 2009:94). So word openbare ruimte (die put), private ruimte. Deur die proses van interpersoonlikheid word die vrou deel van die dissipelgroep van Jesus (Malina \& Rohrbaugh 1998:99).

Volgens sosiale-identiteitsteorie val alle sosiale situasies iewers tussen hierdie twee uiterstes (Jesus en die Samaritaanse vrou), en gedrag teenoor mense word geklassifiseer as deel van die binnegroep of die buitegroep. Hierdie gedrag word beïnvloed deur individue se persepsies van die situasie. In die besonder was dit Jesus van die binnegroep wat 'nader aan die situasie was' omdat hy meer eenvormigheid getoon het in sy gedrag teenoor lede van buitegroep (Samaritane), en bereid was om individuele verskille met 'n buitegroeplid te ignoreer en haar nie te behandel as 'n ongedifferensieerde persoon wat deel is van 'n amorfe sosiale kategorie nie.

Die interaksie tussen Jesus en die Samaritaanse vrou bring 'n vorm van (spirituele) status, 'sosiale verandering' en 'sosiale mobiliteit' teweeg. Sosiale verandering is 'n verandering in die aard van die verhoudings tussen grootskaalse sosiale groepe, soos sosioekonomiese, nasionale (Jood teenoor Samaritane), godsdienstige en rasse- of etniese kategorieë. Sosiale mobiliteit is individuele mobiliteit. Dit beteken dat mense beweeg van een sosiale posisie na 'n ander. Dit gebeur wanneer die vrou Jesus herken as die Messias in Johannes 4:25 en 42. Die Samaritaanse vrou het in die proses van verandering van een sosiale posisie (buitegroep) na 'n ander beweeg (binnegroep); en so word sy modus ponens deel van die Jesus-groep. Die modus ponens-argument kan soos volg uitgedruk word: In die teologie van Johannes kom dit duidelik na vore binne die metaforiese raamwerk van die familie-metafoor soos wat Van der Watt (2000) en later ook Kok (2016) aangetoon het. In die dualistiese denke van Johannes is 'n mens deel van een van twee families - die van God as Vader (vgl. Joh. 1:12) of die duiwel as vader (Joh. 8:44). Diegene wat tot geloof kom in Johannes se wêreldbeeld, ontvang die reg om kinders van God genoem te word ( $\tilde{\delta} \delta \omega \kappa \varepsilon v$

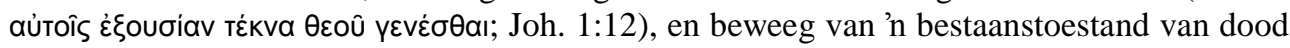
oor na 'n bestaanstoestand van lewe ( Vanuit die perspektief van die modus ponens-argument kan geargumenteer word dat haar spirituele blindheid genees word (kyk Joh. 9:40-41; 12:40-41), en sy geestelike 'sig' en 'lewe' ontvang (Joh. 3:16). Verder word die Samaritaanse vrou in Johannes effektief 'n missionale getuie voordat die dissipels in Johannes missionaal optree (Kok 2016). Vanuit 'n performatiewe (en protreptiese) perspektief kan geargumenteer word dat sy dus dien as 'n prototipe van die 'korrekte' gedrag vir die implisiete leser.

Hierdie perspektief of argument kan verder versterk word deur te let op die woorde wat Johannes in die opgestane Jesus se mond plaas in Johannes 20:21: "Net soos die Vader my

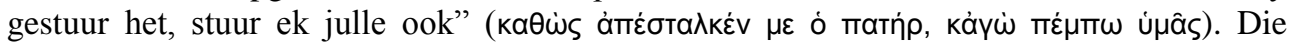


sending van Jesus (Joh. 3:16) moet volgens Johannes uitloop op die sending na die wêreld

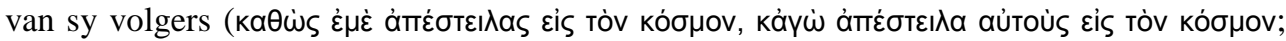
Joh. 17:18). Reeds in Johannes 4 word die Samaritaanse vrou die ideale voorbeeld van 'n missionêre getuie van Jesus. Die teks maak dit immers duidelik in Johannes 4:39 dat die vrou die goeie boodskap na die Samaritaanse stad geneem het en dat baie mense tot geloof

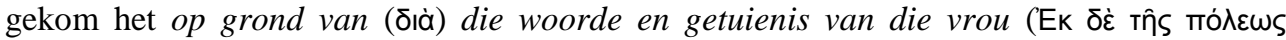

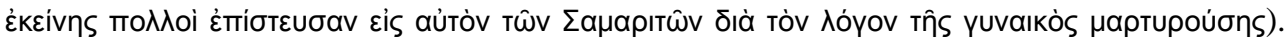
Daarom is Bultmann (1941:148) korrek as hy opmerk: "Dieser Gedanke ist stark betont: wohl war das zeugnis der Frau für die Leute die notwendige vorausetzung ihres Glaubens" (Hierdie gedagte word sterk beklemtoon: waarskynlik was die getuienis van die vrou vir die mense die noodsaaklike vereiste van hul geloof). Op hierdie wyse sluit die betrokke hoofstuk aan by die sogenaamde 'plenipotentiary 'Leitmotif' van die evangelie volgens Johannes (aldus Kok 2015:1-9).

\section{Samevattende opmerkings}

In terme van sosiale-identiteitsvorming in Johannes 4 is die sosiale groep van Jesus en sy dissipels die binnegroep. Hierdie groep beskou hulself as behorende tot dieselfde sosiale kategorie (Joh. 1:12; 3:16), en vorm deur vereenselwiging met mekaar 'n binnegroep wat deur 'n proses van sosiale vergelyking, die Samaritane as 'n buitegroep beskou. In die geval van individuele identiteit is die basis van identiteitsvorming die rol waarmee individue hulself vereenselwig (as dissipels van Jesus), asook die betekenis en verwagtinge wat aan hierdie rol gekoppel is (Tajfel 1978:149-178).

Verskillende strategieë word gewoonlik gebruik in 'n poging om iemand uit 'n buitegroep tot'n binnegroep oor te bring (sosiale verandering). Wat sosiale identiteit betref word 'n beoogde samehorigheid bereik deur 'n proses van gelykskakeling (Jesus ontmoet die vrou by die publieke plek). Die gelykskakeling gebeur wanneer Jesus in gesprek tree met die Samaritaanse vrou, en verskille tussen sosiale identiteite sover as moontlik onderdruk of uitskakel (Jode teenoor die Samaritane en man teenoor vrou) en die klem laat val op die eenvormigheid van die groep (kyk bv. Joh. 4:21; almal sal in die toekoms die Vader aanbid, maar nie by Geresim of in Jerusalem nie). Verskille kom slegs ten opsigte van eksterne verhoudinge in die visier - om die afstand van die buitegroep (of -groepe) af te baken. In sy gesprek met die vrou, transendeer Jesus hierdie grense deur private ruimte tot publieke ruimte by die put om te skakel.

Wat individuele identiteitsvorming betref, word gewoonlik 'n strategie van differensiasie gevolg deurdat die Samaritaanse vrou se profiel geteken word op grond van die spesifieke rol waarmee sy haar vereenselwig - in teenstelling met ander moontlikhede. Dit beteken ook dat die groep as 'anders' beskou word (soos aanbidding). In sosiale-identiteitsteorie word die groep as 'n versameling van soortgelyke individue beskou. Hulle vereenselwig hulle met mekaar en huldig dieselfde oortuigings, in teenstelling met lede van 'buitegroepe' (Joh. 4:20). In individuele-identiteitsteorie word die groep as 'n versameling van onderling verbonde individue beskou, waarbinne die individu egter unieke funksies vervul, soos toe die Samaritaanse vrou getuig het (Tajfel 1971:149-178).

Dit beteken dat die individuele-identiteitsteorie 'n uiteenlopende (divergerende) en die sosiale-identiteitsteorie 'n saambindende (konvergerende) effek veronderstel. Dit word veral duidelik wanneer die verskillende vorme van identiteit aan die gang gesit word, dit wil sê, wanneer daar ooreenkomstig die gekose of toegeëiende identiteit in konkrete situasies opgetree word (Joh. 4:42). In albei vorme van identiteit word aanvaar as 'n dinamiese proses waarop sowel die aanvaarde identiteit as die spesifieke omstandighede ' $n$ invloed 
uitoefen. In die geval van sosiale identiteit is die moontlike alternatiewe minder, omdat individuele verskille ter wille van die gemeenskaplike identiteit onderbeklemtoon en

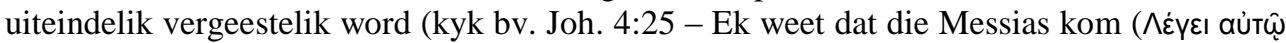

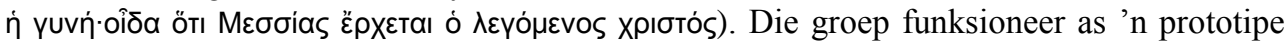
waarby die individu aanpas, en nie andersom nie. Hierdie proses vorm die grondstruktuur van alle stereotipes, wat altyd 'n mate van veralgemening en uiteindelik vergrowwing en vertekening meebring (kyk bv. Joh. 4:42 - "Ons glo nie op grond van wat jy vertel het nie, en ons weet dat Hy waarlik die Verlosser van die wêreld is"). Dit is logies dat as die groep groter word (Joh. 4:39 -baie van die Samaritane in daardie dorp het tot geloof in Jesus gekom op grond van die woorde van die vrou wat getuig het) - die beperking en vertekening nog groter word. Daar vind dus 'n mate van ontpersoonliking plaas, waarvolgens die Samaritane van Sigar hulle eerder met die sosiale kategorie as met die individu as sodanig vereenselwig.

In Johannes 4:1-42 word nie net die gebroke verhouding tussen die Samaritaanse vrou en God herstel nie, maar daar is ook potensiële restourasie van die gebroke verhouding tussen die Samaritane en die Jode wat in die nuwe familie van God gebore word (Joh. 1:12). Jesus se kommunikasie met die Samaritaanse vrou is dus meer as 'n blote kommunikatiewe interaksie; dit kan gesien word as 'n transformatiewe interaksie, 'n prototipe van 'n restourasie van verteenwoordiging (Kok 2008:323). Een van die anonieme eweknie beoordelaars van hierdie artikel het tereg opgemerk dat "[T]he further reaching effect of the Gospel (mutual indwelling/'in-grouping' between people and God, and the agency of believers to become those who 'in-group' outsiders [2 Cor. 5:18])”. Dit is hierdie belangrike dimensie van versoening wat ons dus hier in Johannes ook vroeër terugvind in Paulus (vgl. 2 Kor. 5:18) en wat tot 'n kardinale dimensie van die Jesus-beweging hoort (sien ook 1 Kor. 12:13; Gal. 3:28 en Kol. 3:11).

Peter Anibati-Abia (2013:5-6) is dus korrek as hy opmerk dat Jesus in Johannes uitgebeeld word as 'n ware brugbouer: "[B]y reaching out to such a notorious woman, Jesus is truly depicted as the one who shows mercy to the tax collectors, prostitutes and all the outcasts of the Jewish people (Mark 7:24-30; Luke 7:36-50, 10:25-37)".

Johannes 4:1-42 funksioneer dus as sub-narratief om die kerndoel van die Evangelie (Joh. 20:30-31) te bereik, naamlik om te dien as teken dat Jesus waarlik die Seun en die bron van Lewe is, die nuwe (ware) tempel (Joh. 2:17-22), en diegene wat dit glo, die ewige lewe sal ontvang (Joh. 3:16; 20:30-31).

\section{LITERATUURVERWYSINGS}

Abia-Anibati, P 2013. "A Missional Perspective of John 4:1-42: Hearing Jesus and the Samaritan Woman and its Implications for the Mission of the Contemporary Church", Unpublished MA-thesis, University of Pretoria.

Albright, WF 1956. 'Recent Discoveries in Palestine and the Gospel of St John', in WD Davies \& D Daube (eds.), The Background of the New Testament and its Eschatology: In Honour of CH Dodd, pp. 153-171, Cambridge University Press, Cambridge.

Billing, M, \& Tajfel H 1973. 'Social Categorization and Similarity in Intergroup

Behaviour', European Journal of Social Psychology 3:27-52.

Bultmann, R 1941, Das Evangelium des Johannes, Vandenhoeck \& Ruprecht, Göttingen. 
Capozza, D \& Brown, R 2000. Social Identity Processes: Trends in Theory and Research, Sage, Thousand Oaks.

Esler, PE 2003. Conflict and Identity in Romans, Fortress Press, Minneapolis.

Joubert, S \& Van Aarde A 2009. "Social-scientific Criticism”, in Du Toit, AB (red.), Focusing on the Message, pp. 417-455, Protea, Pretoria.

Kippenberg, HG 1971. "Garzim und Synagoge, Traditionsgeschichtliche Untersuchungen zur samaritanischen Religion der aramäischen Periode“, Religionsgeschichtliche Versuche und Vorarbeiten 30:87-93.

Kok, J 2008. "Siekte en gebrokenheid teenoor genesing en restourasie in Johannes", Ongepubliseerde PhD-tesis, Departement Nuwe Testamentiese Wetenskap, Universiteit van Pretoria.

Kok, J 2015. "The plenipotentiary idea as Leitmotiv in John's Gospel," In die Skriflig 49(2):1-9. doi: 10.4102/ids.v49i2.1923.

Kok, J 2016. New Perspectives on Healing, Restoration and Reconciliation in John, BINS 146, Brill, Leiden.

Malina, BJ \& Rohrbaugh RL 1998, Social Science Commentary on the Gospel of John, Fortress Press, Minneapolis.

Neyrey, JH 2009. The Gospel of John in Cultural and Rhetorical Perspective, William B Eerdmans Publishing Company, Grand Rapids.

Snodgrass K 2018. Stories with Intent: A Comprehensive Guide to the Parables of Jesus, Eerdmans, Michigan.

Tajfel, H \& Turner, JC 1986. 'An Integrative Theory of Intergroup Conflict', in WG Austin \& S Worchel (eds.), The Social Psychology of Intergroup Relations, pp. 33-47, Brooks/Cole Publishing, Monterey.

Tajfel, H 1978. Differentiation between Social Groups: Studies in the Social Psychology of Intergroup Relations, Academic Press, London.

Tajfel, H 1981. Human Groups in Social Categories: Studies in Social Psychology, Cambridge University Press, Cambridge.

Tajfel, H 1982. Social Identity and Intergroup Relations, Cambridge University Press, Cambridge.

Tucker, BJ \& Baker CA (eds.) 2014. T\&T Clark Handbook to Social Identity in the New Testament, Bloomsbury T\&T Clark, New York.

Turner, JC 1987. Rediscovering the Social Group: Self-categorization Theory, Blackwell, New York.

Turner, JC 1996. 'Henri Tajfel: An Introduction', in WP Robinson (ed.), Social Groups and Identities: Developing the Legacy of Henri Tajfel, pp. 1-24, ButterworthHeinemann, Oxford. 